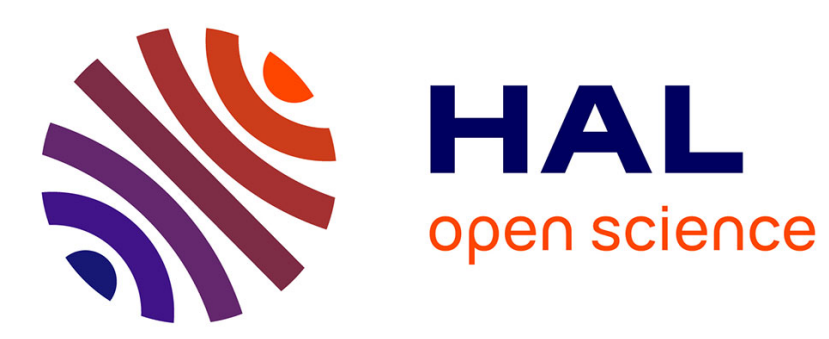

\title{
Robotics: Hephaestus Does It Again
}

Jean-Paul Laumond

\section{To cite this version:}

Jean-Paul Laumond. Robotics: Hephaestus Does It Again. Robots and Art: Exploring an Unlikely Symbiosis, Springer Singapore, pp.67 - 86, 2016, 978-981-10-0321-9. 10.1007/978-981-10-0321-9_5 . hal-01376739

\section{HAL Id: hal-01376739 \\ https://hal.science/hal-01376739}

Submitted on 5 Oct 2016

HAL is a multi-disciplinary open access archive for the deposit and dissemination of scientific research documents, whether they are published or not. The documents may come from teaching and research institutions in France or abroad, or from public or private research centers.
L'archive ouverte pluridisciplinaire HAL, est destinée au dépôt et à la diffusion de documents scientifiques de niveau recherche, publiés ou non, émanant des établissements d'enseignement et de recherche français ou étrangers, des laboratoires publics ou privés. 


\section{Robotics: Hephaestus does it again ${ }^{1}$ \\ Jean-Paul Laumond}

Abstract: After browsing through half a century of robotics research, the chapter emphasizes on motion autonomy as the key attribute of robots. The presentation follows a guiding thread inspired by an ancient myth accounting for the universally debated relationship between science and technology. In Greek mythology, Hephaestus was a talented craftsman. Enamoured with Athena, he attempted to seduce her, in vain. The goddess of "knowing" withstood the advances of the god of "doing". Robotics stems from this tension. Although the myth contradicts a current tendency to confuse science and technology, it nevertheless reflects the experience of the author as a roboticist.

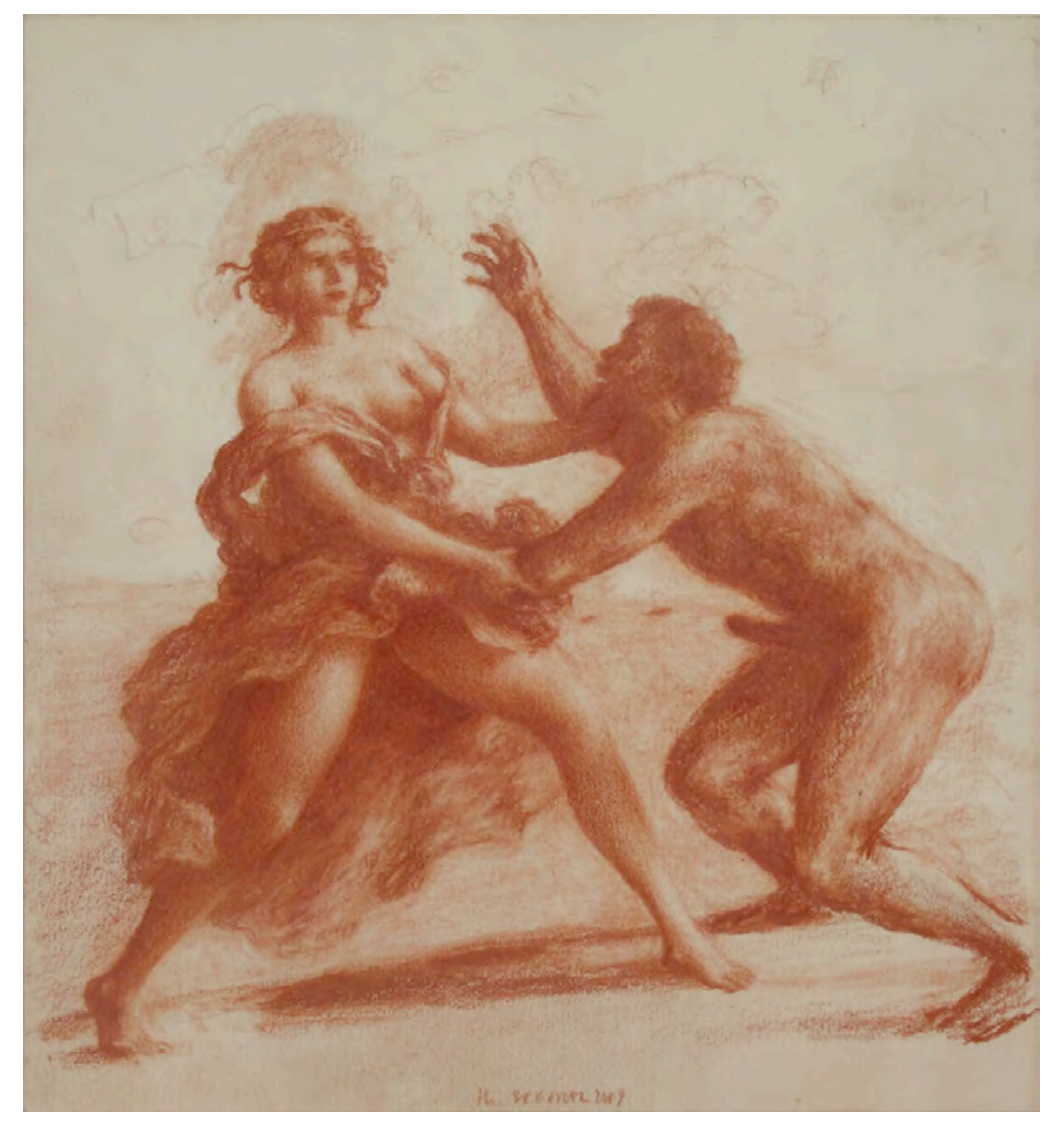

Philippe Ségéral,

Athéna et Héphaïstos, Etude (2009), Private collection

\footnotetext{
${ }^{1}$ The text is adapted from the inaugural lecture delivered on the January 19, 2012, in the framework of Liliane Bettencourt Chair of Technological Innovation at Collège de France in Paris. It benefits from the translation by Liz Libbrecht of the original version entitled La robotique : une récidive d'Héphaïstos, and published in Collège de France / Fayard Collection «Leçons inaugurales du Collège de France », n 224, May 2012.
} 
Robotics explores the relationship that a machine which moves, and whose motions are controlled by a computer, can have with the real world. In this sense the robot differs from automats, whose motions are mechanically determined, and computers, which manipulate information but do not move.

What degree of autonomy can such machines be expected to have? This question does not cover robotics entirely, but it does account for a large part thereof, and it has a certain ambition. In particular, it resonates with the sciences that take living beings, including humans, as their research objects. We can however immediately underline an essential difference: the roboticist has to make robots; the neurophysiologist, the bio-mechanical researcher or the psycho-physicist seeks to understand humans and animals. Words have their significance. The missions differ: while the former have to $d o$, and are condemned to innovating, the latter have to understand, and are condemned to producing knowledge.

The distinction between doing and understanding is not new in the history of science; Pasteur's quadrant aims to show that. It was introduced recently from a perspective of management and evaluation of research ${ }^{2}$. It structures sciences, technologies and their relations along two axes: one concerns the more or less fundamental nature of research; the other its usefulness. In this quadrant, robotics would fit in with Edison, under "applied research with a strong societal impact" - an expression that allows for a presentation of the discipline. But robotics is an activity that is not summed up so easily. I prefer not to "resolve" the tension between doing and understanding, and to that end I refer to a Greek myth that will serve as my main theme.

It was when I was preparing my lecture at Collège de France in 2011 that I discovered that roboticists have a god: Hephaestus. In Greek mythology, Hephaestus was an ingenious, talented craftsman, known for the remarkable weapons he made. But he also made wheelchairs that moved about on their own (basically, mobile robots) and golden servants that helped him to move about (basically, servicing robots), and he even made Pandora, a clay statue to whom Athena gave life. He had a tumultuous love life, as attested by the following passage by Apollodorus ${ }^{3}$, a chronicler from the second century BCE:

Athena visited Hephaistus, wanting to fashion some arms. But Hephaistus, who had been deserted by Aphrodite, yielded to his desire for Athena and began to chase after her, while the goddess for her part tried to escape. When he caught up with her at the

\footnotetext{
${ }^{2}$ Stokes DE (1997) Pasteur's Quadrant - Basic Science and Technological Innovation. Brookings Institution Press

${ }^{3}$ Hard R (1997) The Library of Greek Mythology / Apollodorus. Oxford: Oxford University Press, p. 132.
} 
expense of much effort (for he was lame), he tried to make love to her. But she, being chaste and a virgin, would not permit it, and he ejaculated over the goddess's leg. In disgust, she wiped the semen away with a piece of wool and threw it to the ground. As she was fleeing...

While Hephaestus is the god of doing, Athena, who appears here as the one who calls the tune, is the goddess of knowing or - to protect me from reprimands from the exegetes - let me consider her as such for the purpose this lecture. Hephaestus was thus seeking to possess Athena. He was unable to do so. Could the doing not aspire to the knowing? A hard blow for the roboticist.

Robotics stems from this tension. Although the myth contradicts a current tendency to confuse science and technology, it does nevertheless reflects my own experience regarding innovation - experience that I might sum up as follows: even though doing is not understanding, understanding enables one to do, but unfortunately, not always. And even though one may very well do without understanding, doing also enables one to have tools sometimes surprising ones - for understanding.

I am going to illustrate my argument in three parts: two concern algorithms used to plan motion, while the third concerns humanoid robots and recent models of anthropomorphic action. But first, let us look at a few historical milestones that enable us to situate the discipline and its fields of application better.

Robotics is 50 years old or, more precisely, 54. Although the word robot appeared early in the $20^{\text {th }}$ century and has since fuelled a collective imaginary, the birth of robotics is generally pinpointed to the introduction, in 1961, of the first industrial robot on the General Motors assembly lines. This was the Unimate robot, patented by George Devol and industrialized by Joseph Engelberger, recognized as the founding father of robotics. From the outset, numerical control machines were the most salient feature of robotics research, along with the establishment of the first connections between machines and computers, mechanics and informatics. These beginnings were soon to be accompanied by technological progress in calculation (miniaturization and enhanced power of processors).

Robotics is now well established in the manufacturing sector, where it has had a significant part to play in altering the organization of the means of production. Its success is related to the repetitive nature of the tasks that industrial robots perform (welding, painting, sorting, transporting, etc.) in well-structured environments where problems are usually limited to 
engine failure or can be treated by an emergency stop. There is no need for a high level of adaptability in these environments.

The question of the autonomy of a computer-controlled machine as such arose in the late sixties only. At Stanford Research Institute (SRI), work with the mobile robot Shakey laid the foundations of research on autonomous robots. The main aim was to equip machines with the ability to reason on their actions. A robot had to perceive its state and the state of the world surrounding it (for which it was equipped with sensors), and to act (for which it was equipped with actuators enabling it to move about). The computer then "simply had to" decide automatically on the actions to perform to fulfil a specific mission and check that everything was running smoothly.

In fact the SRI researchers had no particular application in mind. At the time, robotics was seen as a possible field of application for the theories developed in artificial intelligence. It was more a dream than a project to solve specific problems concerning robots in industry.

It was in the eighties that the first scientific societies and professional federations devoted to robotics were founded: the Robotics and Automation Society (IEEE) in 1984, the International Foundation on Robotics Research (IFRR) in 1986, and the International Foundation of Robotics (IFR) in 1987. During the same period, at the 1982 Versailles Summit, the industrialized countries adopted the International Advanced Robotics Programme (IARP) devoted to scientific cooperation in the field of robotics.

Everything started to speed up in the nineties.

In 1993 the company Honda disclosed the results of seven years of research carried out in complete secrecy: P1, an anthropomorphic robot, took its first steps. In the same year, under the Rotex project headed by Gerd Hirzinger at the $\mathrm{DLR}^{4}$ in Germany, an on-board manipulator robot on a space shuttle grasped an object floating in space and assembled mechanical parts. On 4 July 1997, the NASA robot Sojourner started its walk on Mars. It was to be followed by the robots Sprit and Opportunity in 2004 for missions that are still on-going today. On 11 May 1999, the company Sony put the first toy robot on the market: a small dog capable of moving about, perceiving its environment and recognizing human orders. On 7 September 2001, Professor Jacques Marescaux conducted the first tele-surgery on a patient hospitalized in Strasbourg, with the help of a surgical team situated in New York. In 2002 the company iRobot, set up in Boston by Rodney Brooks from MIT, commercialized Roomba, the first vacuum-cleaner robot, of which millions have now been sold. In 2005 a team from

\footnotetext{
${ }^{4}$ Deutschen Zentrum für Luft- und Raumfahrt (German space agency).
} 
Stanford University, headed by Sebastian Thrun, won the DARPA Grand Challenge: his vehicle was the first to cover 200 kilometres in less than seven hours in the Mojave desert, with total autonomy. In the same year at the Aichi exhibition in Japan, Toyota presented a jazz orchestra composed of humanoid robots playing various wind instruments. The quadruped robot Bigdog, by the company Boston Dynamics founded by Marc Raibert from MIT, was tested in Afghanistan on 25 March 2009. In the spring of 2011, in the team of François Pierrot at LIRMM lab in Montpellier, the parallel robot R4 reached an acceleration of 100 G. Finally, to date, more than 6,000 Naos, small humanoid robots, have been produced by the company Aldebaran.

What knowledge is built around this profusion of innovation?

Robotics grew out of mechanics. It participated in the emergence of disciplinary fields such as control theory and signal processing, borrowing from computer science and feeding into algorithmics. After the appearance of Unimate, nearly two decades passed before the first attempts were made to theorize this field that was still seeking its bearings.

Two major schools of thought were to revive old debates rooted in the humanities, to apply them to the study of autonomous machines and to structure research in robotics.

The supporters of what, with hindsight, could be called a "robotics phenomenology", argued for the primacy of the model and introduced the "perception-decision-action" loop: the robot uses its sensors to assess its own state and the state of the world surrounding it; it then devises models of those states, reasons on the basis of the models, and decides on the actions to perform to fulfil the mission assigned to it. This school has never really been theorized ${ }^{5}$. It is structured around topics such as:

1. mechanical system design and control;

2. artificial vision and, more generally, artificial perception;

3. object manipulation;

4. algorithmic action planning and control;

5. system architecture.

It is this school that has headed large programmes in manufacturing robotics, medical robotics and planetary exploration robotics.

The other major current is the school led by Rodney Brooks, the charismatic researcher from MIT. In the eighties Brooks argued for a conception of autonomy based on the absence of

\footnotetext{
${ }^{5}$ With the exception of an attempt by John Hopcroft, more a theoretician of computing than a roboticist, who saw in robotics the emergence of a "stereo-phenomenology". This he described in an article that, strangely, remained confidential: Hopcroft JE (1986) The impact of robotics on computer science. Communications of the $A C M$, vol. $29, \mathrm{n}^{\circ}$ 6:486-498, DOI: $10.1145 / 5948.5949$.
} 
models of the world: the machine's intelligence should emerge from a hierarchy of sensorymotor behaviours managed by exciter and inhibitor mechanisms ${ }^{6}$. This school of thought spawned a type of robotics said to be "bio-inspired". It had far less contact with industry than did the preceding one. The robot was considered above all as an experimental medium for theories from the life sciences. This was the school from which strange artificial creatures were born, such as the amphibian salamanders ${ }^{7}$ of Auke Ijspeert at the EPFL in Lausanne. Dialogue between the two communities went via the elaboration of mathematical models. Observation of life also gave birth to very clever formal approaches, such as the one developed by Nicolas Franceschini ${ }^{8}$, which enabled a drone to land softly, based on the principles highlighted by the study of flying insects.

In fact, this separation into two schools is not as distinct today. The tendency of the two schools to move closer together is a fundamental one. It is evidenced in the 1,600 pages of the first encyclopaedia of robotics, published only six years ago ${ }^{9}$.

In the introduction we saw that a robot acts through motion. Its autonomy therefore depends primarily on its ability to "decide" on its actions. So let us start with the question of the automatic motion computation.

Industrial robots have to perform tasks in welding, painting and assembling mechanical parts. A mobile robot - be it the robot exploring Mars, the future car, or the next factotum robot that will share our offices - has to be able to move about, to avoid obstacles in its way, and to inspect a place. If it is equipped with manipulator arms, it will also have to manipulate objects.

What methods should be developed so that the machine-computer twosome can reach an objective without an operator having to specify every detail of the motions required?

Suppose the robot is perfectly familiar with its environment and is able to situate itself therein: for example, it has access to a layout plan of the place in which it operates (this plan was either given to it, or it acquired it through its sensors) and the environment in which it works has already been modelled numerically (in the case of the industrial robot). In short, the

\footnotetext{
${ }^{6}$ Brooks RA (1991) Intelligence without representation. Artificial Intelligence, vol. 47, p. 139-159, DOI: 10.1016/0004-3702(91)90053-M.

${ }^{7}$ Ijspeert AJ, Crespi A, Ryczko R, Cabelguen JM (2007) From swimming to walking with a salamander robot driven by a spinal cord model. Science, vol. 315, n ${ }^{\circ}$ 5817, p. 1416-1420, DOI: 10.1126/science.1138353.

${ }^{8}$ Ruffier F and Franceschini N (2005) Optic flow regulation: the key to aircraft automatic guidance. Robotics and Autonomous Systems, vol. 50, n 4, p. 177-194, DOI: 10.1016/j.robot.2004.09.016.

${ }^{9}$ Khatib O, Siciliano B (eds) (2008), Springer Handbook of Robotics, Springer Verlag.
} 
geometry of the place is known to the machine. In these conditions, how can a computer compute a motion to make, based on an initial position, to attain a set goal? How can it avoid obstacles? How can it be sure whether the goal can be attained or not? The problem posed in this way has been popularized in robotics by the evocative expression "the piano mover's problem". It is one of the most emblematic problems in robotics.

Can a computer answer this question? To give meaning to this type of query, our computer scientist colleagues use the notion of decidability. When a problem is decidable, either the computer provides a solution, if one exists, or it supplies exact information on the nonexistence of a solution. The question is then precise: is the piano mover's problem decidable? The answer is yes. This was demonstrated in two steps in the early eighties.

In the first step, Tomás Lozano-Pérez (MIT) suggested transforming the problem of moving a body in space, into a problem of moving a point ${ }^{10}$. Thus, if one can "reduce" the piano into a ping-pong ball, the problem is far simpler. But how does one go about doing that?

To situate a rigid body in space, three position parameters and three rotation parameters are necessary. These six parameters correspond to the coordinates of a point in space, called the configuration space. The configuration space will be reduced to three parameters for a rigid body moving in the plane (a car, for example). More generally, it will consist of several articular parameters for a manipulator robot, and of about thirty parameters for a humanoid robot.

The problem which, for a robot, consists in finding a motion without collision in an environment filled with obstacles (our three-dimensional real world) is thus transformed into a problem of seeking a path for a point moving through an abstract space (the configuration space whose dimensions depend on the complexity of the robot considered) and avoiding obstacles, that is, images in this space of obstacles in the real world. In mathematical terms, this consists in exploring the connected components of the configuration space without collision. This is the second step.

Since Deep Blue beat Garry Kasparov at chess, we have known that a computer has the ability to explore highly complex spaces. But the situation in a chess game, although complex, is intrinsically finite: the number of states of the game is finite (albeit huge), and transitions between two states are instantaneous. They correspond to only a few rules concerning the motion of the various pieces on the chessboard. In the case of planned motion, the problem is very different. A motion is a continuous function of time in space. How can a

\footnotetext{
${ }^{10}$ Lozano-Pérez T (1983) Spatial planning: a configuration space approach. IEEE Transactions on Computers, vol. C-32, nº 2, p. 108-120, DOI: 10.1109/TC.1983.1676196.
} 
computer solve this problem of continuity when it is condemned to computing everything? In other words, how can this problem, which is continuous by nature, be rendered combinatorial?

Lozano-Pérez provided a solution in the case of a polygon moving in translation on a plane. But is this possible in other cases? The question appealed to mathematicians and experts in combinatorics, especially Jacob T. Schwartz and Micha Sharir of the Courant Institute of Mathematical Science in New York. In 1983 they published a general solution to the problem, valid for any type of mechanical system ${ }^{11}$. The idea of the demonstration was based on a method for reducing the piano mover's problem to an elementary algebraic problem of decidability (established in the 1950s by mathematician Alfred Tarski), and on an algorithm proposed by mathematician George E. Collins in the seventies. The algorithm was complete: the computer would give a solution if there was one and would otherwise affirm with exactitude the absence of a solution.

With reference to the myth, let's say that Athena had won: she knows what to do.

Was the problem solved? Not really. Or rather, it was indeed solved, but not "usefully". In fact, the complexity of the algorithm (that is, the computation time needed to execute it) is a major impediment to its application. The algorithm is doubly exponential in the dimension of the configuration space. It takes too much time: Hephaestus does not care about a powerful solution in theory if it is ineffective in practice. The mathematicians of real algebraic geometry continued to explore this route. They were reducing the complexity of algorithms but progress was slow and the research difficult. There seemed little hope of them ever being useful in motion planning ${ }^{12}$.

That was in the 1980s. A whole section of this research was to break away from robotics applications to contribute to fledgling computational geometry. Particular problems in low dimension spaces were to be solved elegantly: there is finesse in Delaunay's triangulation, in its dual, Voronoï's diagram, and in Minkowski's convolutions of polygons. At INRIA in France, these structures of geometric data were to serve to minimize the wastage of leather in the tawing industry (imagine having to fit as many right hands and left hands as possible onto a piece of leather, to produce as many gloves as possible!). Thus, Athena scored a small point, even though considerable efforts were still required to obtain the "exact" calculation that these

\footnotetext{
${ }^{11}$ Schwartz JT, Sharir M, On the 'piano movers' problem II: General techniques for computing topological properties of real algebraic manifolds. Advances in Applied Mathematics, vol. 4, $\mathrm{n}^{\circ} 1$, p. 298-351, DOI: 10.1016/0196-8858(83)90014-3.

${ }^{12}$ Real algebraic geometry does nevertheless have real applications in robotics. In the case of parallel robots known for their speed and precision, it serves to avoid design errors.
} 
methods required. It was to take large research projects, like the CGAL project in Europe, to accomplish that.

This knowledge nevertheless had little influence on programmes set up to develop robotics.

In 1990 I spent a few months at Stanford University. Jérôme Barraquand and Jean-Claude Latombe had just devised a new approach ${ }^{13}$ consisting in extending a local research method developed by Oussama Khatib a few years previously: the potential method ${ }^{14}$. The method is applied in the configuration space. The starting point is attracted by the goal to reach, while being repulsed by the obstacles situated on its path as it progresses. The attractive and repulsive potentials generated respectively by the goal and the obstacles combine to produce a field of potential. An algorithm to monitor the steepest slope (the gradient) makes it possible to progress towards the goal. Although effective in practice, the method nevertheless has the drawback of stopping in areas of no slope, that is, potential wells that do not necessarily correspond to the goal.

Barraquand and Latombe had the idea, or I could say the audacity, to introduce random steps into these cases. The algorithm thus consists of a sequence of alternating gradient descents and random steps. How can one prove that the goal can be reached in this way? One cannot. Or rather, one can prove that if a solution exists to the problem, then there is a sequence of indefinite length that will find it. And if there is no solution, the algorithm will "loop" to infinity. In practice, it will be stopped after a certain calculation time, and there one will find oneself without a solution or any guarantee that there is not one. One cannot say that the piano mover's formal problem is solved. Yet the results are spectacular. A student did a demonstration for me on a system consisting of eight articulated bars (dimension eight configuration space - a dimension until then out of reach of any other method): the "robot" wove its way through a highly cluttered space after only a few seconds of calculation. I was flabbergasted by the ease with which it did so. Familiar with the problem, I suggested that the student run his program based on a very particular starting configuration, drawn by a very deep well of potential. After calculating for more than a night, the program had found no solution, whereas we knew that there was one. Morality was safe: there was no miracle. Hephaestus' know-how had not been promoted to the ranks of knowledge.

13 Barraquand J, Latombe JC (1991) Robot motion planning: a distributed representation approach. The International Journal of Robotics Research, vol. 10, $\mathrm{n}^{\mathrm{o}}$ 6, p. 628-649, DOI: 10.1177/027836499101000604.

${ }^{14}$ Khatib O (1986) Real-time obstacle avoidance for manipulators and mobile robots", The International Journal of Robotics Research, vol. 5, $\mathrm{n}^{\circ}$ 1, p. 90-98, DOI: 10.1177/027836498600500106. 
The problem remained whole. The problem remained whole? Of course! Except I had devised a very particular case deliberately to "trap" the algorithm. Usually it actually worked very well.

Intrigued, on my return to Stanford I launched research on a subject that can be summed up in the question: Why does the method work "so well"? After working for a year with a $\mathrm{PhD}$ student ${ }^{15}$, I was able to identify the type of mathematics that could account for performance: it concerned theories of "catastrophe" and "percolation". I went to Toulouse to give a seminar in a static physics laboratory, and there I met specialists who very quickly understood the nature of the problem that we were focusing on. Jokingly, they suggested I join their laboratory so that we could work on it together. For me that would have meant giving up robotics. Understanding the behaviour of these methods is indeed a very difficult problem that is still unsolved today. When we returned from this seminar my PhD student and I agreed to change the subject of his thesis. Hephaestus was enraged at having to give up. But so what: he had opened the door to the development of probabilistic methods.

Unlike the methods spawned by algebraic geometry or computational geometry, probabilistic methods require no explicit construction of obstacles in the configuration space. A simple checker of collision between bodies in real three-dimensional space is enough to implement them. In its basic version ${ }^{16}$, the probabilistic algorithm draws configurations randomly: if a configuration is in a space free of obstacles (test obtained by the application of the collision checker), it is added to the data structure. We then verify if it is possible to connect it via a collision-free path with other configurations already computed. If it is, we memorize the information. The data structure is enriched as the computations are performed, and takes the form of a map, called a graph, which tends to cover the space of obstacle-free paths. Solving a problem of motion planning amounts to verifying whether the departure and the goal are attainable from the points on the graph, and whether these points can be linked up via a sequence of pre-calculated paths. The on-going problem of seeking a path in the configuration space is then reduced to the combinatorial problem of the search for paths on the graph. The shift from continuous to combinatorial is done; that was the aim. The method is simple and general. It is at the origin of numerous variants, each with its own characteristics. They are currently still being developed by several teams around the world and are constantly being

\footnotetext{
${ }^{15}$ Florent Lamiraux, now a senior researcher at the CNRS.

${ }^{16}$ Kavraki LE, Svestka P, Latombe JC, Overmars MH (1996) Probabilistic roadmaps for path planning in highdimensional configuration spaces. IEEE Transactions on Robotics and Automation, vol. 12, $\mathrm{n}^{\circ} 4$, p. 566-580, DOI: $10.1109 / 70.508439$.
} 
improved $^{17}$. They owe their success to the fact that they match up to the state of calculation technology so well. Had they been developed twenty years earlier and presented on the sole basis of their formal contribution, without reference to case studies that processors at the time would have been unable to solve, these methods would not have been published.

Not only are probabilistic methods effective in practice, they are also easy to program. Today they make it possible to plan the complex motions of a humanoid robot transporting cumbersome objects. And they have unexpected applications.

Probabilistic methods are at the origin of a software platform developed at LAAS-CNRS ${ }^{18}$ in the framework of a European project in which industrial firms were participating. Scale one problems were successfully solved by simulating maintenance operations in industrial facilities. In 1999 the French law on innovation was passed. It encouraged researchers to set up their own businesses. The company Kineo was founded in December $2000^{19}$. The idea was to target the virtual prototyping market. In this sector, mechanical assemblage and robot programming solutions have to be validated, based on digital mock-ups. The process takes place in a three-dimensional virtual world, in a design phase preceding production. Technicians explore the digital mock-up on a computer screen, shift around the mechanical parts, and check that they match the specifications. They have to prove, for example, that it is possible to fit a car seat that has just been designed, into the car. If not, the seat has to be redesigned. This is the piano mover's problem viewed from the angle of mechanical assemblage. Whereas the verification could take a technician several hours, probabilistic algorithms solve the problem within seconds. This gain is the value of the computed motion. At the time, a few years were needed to transform a software prototype developed in a laboratory into a product and, among other things, to integrate it into the software packages commercialized by Dassault Systèmes and Siemens. By 2011 the company was managing a portfolio of over 1,700 licences (150 clients in 25 countries) equipping almost all the car manufacturers in the world. The company was acquired by Siemens in 2012. Hephaestus had worked well.

\footnotetext{
${ }^{17}$ Research in this field consists in giving "meaning" to random draws, that is, introducing various laws of distribution of probability, depending on the context. A real engineering of probabilistic algorithms has thus been developed.

${ }^{18}$ Siméon T, Laumond JP, Lamiraux F (2001) Move3D : a generic platform for path planning. In: Proceedings of 4th International Symposium on Assembly and Task Planning, 2001.

${ }^{19}$ Laumond JP (2006) A success story of motion planning algorithms. IEEE Robotics and Automation Magazine, vol.13, $n^{\circ} 2$.
} 
But he was still furious about not understanding the reasons for this success. Let this be clear: the piano mover's problem is well set out; it can be solved on a computer, that has been demonstrated. However, its complexity put its resolution beyond the reach of calculation technology at the time. Remember that by "resolution" we mean that it is possible for a computer to decide on the absence of a solution. In this sense, probabilistic methods are not concerned with solving the problem. Generally they give a solution if one does exist, and that is enough. "Understanding" is another story, that should not slow down the innovation process. There is genius in these methods, that is for sure: it lay in their perfect match with the state of computation technology. Computers in the sixties would not have rewarded the same boldness.

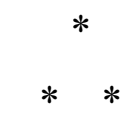

Let us remain in the domain of motion.

In 1985, my mentor Georges Giralt asked me the following question: the piano mover's problem is a well understood problem; to solve it, one simply has to explore the connected components of the configuration space without collision; the underlying hypothesis is that all motion of the mechanical system appears as a path in the configuration space; but what about the converse? Is there a motion that corresponds to every path? In particular, a mobile robot with wheels has to roll without sliding; it cannot move sideways; this is not a piano that the movers can move about any way. The entire preceding construction collapses: it is not because we are going to find a path without collision in the configuration space that this path corresponds to admissible motion for the mobile robot. Parallel parking is a more difficult task than it seems. It requires one to refer back to theory.

From the 1990s and until the end of the 2000s, entire sessions in robotics conferences were devoted to the problem. They no longer exist, and the explanation is simple: the problem has been solved, or rather, today's engineers have everything they need to enable a mobile robot to decide on its trajectories, with total autonomy. Let's look at this in more detail.

In 1986 I proposed a laborious demonstration consisting in cutting and pasting arcs of circles and line segments, and showing that all the paths of a piano could be approximated by the paths of a car of the same size, provided that the car could be manoeuvred. The link was immediately made with non-linear system mechanics: a car is a nonholonomic system, a concept encompassing the fact that a driver can act on two parameters only, the speed and the direction of the car, whereas as for him or her it is a matter of mastering the two parameters of the car's position and its orientation. In other words: the configuration space of a car is three- 
dimensional, while the number of its degrees of freedom is two. More colourfully, we could say that there would need to be another engine if the car were to move like a crab.

Mathematics was to contribute decisively to solving this problem ${ }^{20}$. It was to show the roboticist how steering this crab-like motion could be approached through a sequence of admissible motions. Underlying this were notions of vector fields, of Lie brackets and of subRiemanian geometry. A link had to be established between these notions, and that was a matter of pure (not applied) mathematics, and of combinatorial notions of decidability. Proof was established that to park one's car the number of manoeuvres to make varies like the inverse of the square of the free space. And if the vehicle is pulling a sequence of trailers (like trolleys in an airport), the number of manoeuvres can go so far as to follow an exponential function of Fib $(n+3)$, a formula in which Fib represents Fibonacci's famous sequence of numbers $1,1,2,3,5,8,13, \ldots$ and $n$ corresponds to the number of trailers ${ }^{21}$. This number increases like an exponential function, that is, extremely rapidly. The result indicates that, while it can be conceivable to parallel park a car pulling a caravan, or a tractor pulling a cart, it is not reasonable to expect the same feat from a baggage handler at an airport. It is not that the task is impossible, but it is too complex: the number of manoeuvres would be far too great. And this is not just a question of technology; it is a physical reality. Hephaestus can try as much as he likes, Athena will still mock him. This fine result of combinatorics is based on the knowledge of a somewhat exotic geometry. Knowledge has applications where one least expects them. Engineers do not only need applied mathematics to carry out their innovations, they also need pure mathematics.

The above result is actually a result of existence: it is possible to park a vehicle, under certain conditions. But how does one do this in practice? The roboticist demands "constructive" proof of the result of existence. The mathematician is driven into a corner: in the case of parking a trailer he gave a near complete solution to the problem. The roboticist completed it, and in 1993 the LAAS-CNRS' mobile robot Hilare was able to park its trailer entirely autonomously. This was a first. The result could be generalized to several trailers, if their hitches are centred on the axle of the trailer preceding them (the devil really is in the detail!). On the other hand, the mathematician fails to provide a construction for a general system. The problem is a very difficult, open one: we know how to calculate the trajectories of a mobile robot with two

\footnotetext{
${ }^{20}$ Li Z, Canny JF (eds) (1993) Nonholonomic Motion Planning. Kluwer Academic Publishers.

${ }^{21}$ Risler JJ, Luca F (1994) The maximum of the degree of nonholonomy for the car with $n$ trailers. In: Proceedings of the IFAC Symposium on Robot Control, DOI: 10.1.1.48.2332.
} 
trailers with a centred hitch; we do not know how to do so for a robot with two trailers with an offset hitch.

What lessons can be drawn from these results?

The first lesson: the problem of parallel parking has been solved. In the early 2000 s, I tried to promote the technology in automotive industry. I learnt in a meeting with a programme manager that car manufacturers were not interested in our solutions. The reason was not the feasibility of a possible transfer. It stemmed from the fact that car manufacturers did not want to design automatic driving systems because of legal responsibility in the event of an accident. The driver had to remain the only one responsible for the car's behaviour. Complete automation of driving (that is, a form of autonomy of the vehicle) is not the order of the day. Pity. We'll stop at the computer-aided driving systems that we now see emerging.

The second lesson: if it is really necessary, the engineer will know how to compute trajectories for the system with two trailers with their hitches offset. How is this possible? The story goes as follows. In 2000, Airbus and the French Ministry of Infrastructure launched the "Grand Itinéraire" project to transport the six components of the future Airbus A380 by exceptional convoy from the little town of Langon to Toulouse. The dimensions of the convoy were exceptional. In places the road had to be redesigned, and for that purpose it was necessary to simulate the convoy's trajectory with precision. The Direction Départementale de l'Equipement (DDE) contacted Kineo: a fine opportunity for the start-up to establish its position as a specialist in motion planning and control. However, whereas four out of the six trucks had a trailer with a centred hitch, the other two corresponded to the model of the robot towing two trailers with an offset hitch. Bad luck! Kineo's engineers and researchers from LAAS-CNRS nevertheless developed a numerical optimization method (derived from known methods in applied mathematics) which successfully enabled the simulations of crossing through the villages of Condom and Lévignac. For Kineo the opportunity was too good to miss. The contract would enable it to pay the young company's first salaries. Was the mathematical problem solved? No. The numerical method simply corresponded to the DDE's terms of reference.

Knowledge that is of little interest and new know-how that is sterile from the point of view of advances in knowledge are typical of research and innovation processes.

Let us now turn to the last part of this presentation, devoted to humanoid robots. 
Humanoid robots appeared in the 1970s. Technological advances in mechatronics miniaturization of electronic components and increasing power of electric engines - have enabled their application in research laboratories over the past ten years. There are currently around twenty different prototypes.

Hephaestus is starting all over again with new Pandoras. They are no longer of clay, but mecatronics. And they are animated. The roboticist keeps on asking the question of autonomy: what adaptability can we hope to give these new machines? The analogy between humans and machines has to be made ${ }^{22}$; it cannot be avoided. In the end, does Hephaestus have the keys to knowledge? With his machines that adapt, that "decide" on their actions, what can he tell us about our own "functioning"? The question is both dangerous and beautiful.

The danger is epistemic. Robotics cannot serve as an alibi for biology. A biological model cannot be validated on a robotic platform. Even though models of life forms can be simulated on computer, and robots can be controlled on the basis of these principles - sometimes very effectively -, it is in no way possible to conclude on their validity simply because they are operational in robotics. It is not because a roboticist successfully uses a bio-inspired model that this success says anything about the validity of that model. And conversely, it is not because the roboticist is capable of making a robot navigate in an environment cluttered with obstacles that we know how humans or animals solve the same problem.

Yet the confusion is tempting. It is often recognized. It is maintained by the dangerous use of words. We carelessly go from the "autonomous" machine to the "intelligent" machine, then to the "thinking" or "conscious" or "sensitive" machine and why not even the "romantic" machine (although to my knowledge no one, as yet, has dared to use the latter adjective). We may be astounded at the feat of Toyota's robot playing jazz on a trumpet, but we do need to remember that it "feels" nothing, that it has no "humanity" in its playing. We need to take note of our own transference: some of us have a strange affection for our car, but I don't think that the affection is mutual!

Let us bear in mind the image of the myth - and it is only an image, for even if the roboticist can identify with Hephaestus and can shape Pandora out of clay, he is neither Athena nor Geppetto. He will never give any humanity to clay or wood. A robot is a machine controlled by a computer; nothing else. Although animated, it remains and will remain an inanimate

\footnotetext{
${ }^{22}$ Brooks R (2008) I, Rodney Brooks, Am a Robot. IEEE Spectrum, vol. 45, n6:62-67
} 
object without a soul that becomes attached to our soul [and without] the power of love ${ }^{23}$. Let us allow the demi-gods to talk, let us enjoy works by Fritz Lang and Mary Shelley, and let us not be afraid. But are we actually anxious? That is not so sure. In any case, our Japanese friends aren't, they who are so different from us; they for whom union is possible.

The question of the analogy between humans and humanoid robots is hazardous; it had to be answered. It is also fine and fascinating, provided we give it some rigorous substance.

An anthropomorphic system - the human or the humanoid robot - is a system that is both redundant and under-actuated. Let us clarify these two terms that have the advantage of being specialized and therefore not contaminated by common usage.

Take a human skeleton like the ones that used to be displayed in the biology classes of our schools. It is a set of tens of bones articulated to one another. Giving an angle value for the various joints amounts to defining the skeleton's posture: standing, sitting, running, grasping something in its hand, etc. With all these angles, we again find the notion of a configuration space. To animate its skeleton, the human body has several hundred muscles. They constitute the motor space. The tensions on the muscles cause the values of the joints to vary. The situation of current humanoid robots is simpler: a motor is linked to each articulation. The configuration space and the motor space combine. To grasp a ball on a table, the human and the humanoid robot have to move their hand towards the ball. From a geometric point of view, this task is three-dimensional: three parameters are necessary to situate the ball in space. The robot has about thirty motors; humans have several hundred muscles. That is too many. There is a wide gap between the dimension of the task and the dimension of the motor space. This gap allows for countless ways of attaining the goal: one can use the right hand or the left hand; one can scratch one's head with one hand and grasp the ball with the other; if the ball is on the ground, one can grasp it by bending one's knees or not, depending on what one feels like and how supple one is. A system is redundant when the dimensions of its motor space are greater than those of the task to perform. The notion of redundancy is linked to that of action. An anthropomorphic system is also under-actuated. This characteristic relates to the system's motion in its environment. The angular parameters of the skeleton mentioned above correspond to the skeleton's posture, not its position in the environment (is it close to the blackboard or at the back of the lecture room?). The system therefore has to be placed in its environment: six parameters are enough, as we have seen. The space of the configurations of an anthropomorphic system is thus composed of the articular variables of the skeleton and the

\footnotetext{
${ }^{23}$ Allusion to Alphonse de Lamartine's poem "Milly ou la terre natale": "... objets inanimés, avez vous donc une âmell qui s'attache à notre âme et la force d'aimer?".
} 
six position parameters ${ }^{24}$. No muscle, no motor is in charge of directly varying the position parameters. It is in this sense that the system is said to be under-actuated.

If there is one technological feat that humans have accomplished, it has been the invention of the wheel. A disc turning in a vertical plane, placed on a horizontal plane, starts to roll. The centre of the disc moves forwards. The wheel is "specialized" in moving. While moving about is the privilege of life forms (at least at first view), surprisingly nature did not invent the wheel. The sentence "an anthropomorphic system is under-actuated" means that it does not have motors specialized in motion: humans move about by putting one foot in front of the other and then starting again, that is, by varying the articulations in their skeleton, and therefore by activating a large number of muscles, when two wheels would have been enough. Anthropomorphic locomotion is a far more "complex" task than driving a car: it involves far more motor variables than does driving.

How do all the muscles of the human body coordinate to perform the task of grasping something? How can all the motors of a humanoid robot be coordinated to perform the same task? What trajectory does an individual take to leave a room? How can the trajectory of a humanoid robot be calculated in the same situation? The questions are precise. While some seek to understand and others to do, the formulation that we have introduced shows that they are of the same nature. They question the relationship between the motor space and the physical space. This relationship is a key to understanding our relations to the world. Henri Poincaré set the terms ${ }^{25}$. That is where the power of mathematics lies, in proposing a formulation common to science and techniques, and it is this foundation that is contributing today to the emergence of new fields such as neuro-robotics.

If all the angular variables of a skeleton are known, it is easy to infer the position of the left hand in space: there is only one. The converse is not true. If you know the position of the left hand in space, there is an infinity of angular variables of the skeleton that give the same position of the hand (the skeleton is redundant). They will correspond to an infinity of postures, some of which may be unrealistic. Other criteria are therefore needed to make the selection. Among all the possible positions, you can ask for the most comfortable one, that is, the one that corresponds to the least effort - effort being expressed in the motor space, as the sum of all the forces exerted on the muscles. In this case, an algorithm of numeric optimization will lead to the selection of the best posture. The method applies to redundant

\footnotetext{
${ }^{24}$ It may seem strange to consider six parameters, but all six are indeed needed to situate an astronaut floating in a space shuttle. In everyday life, however, the human being is not a body "floating" in space. He or she moves about on a surface, and three parameters are enough to pinpoint him or her.

${ }^{25}$ Poincaré H (1895) L'espace et la géométrie. Revue de métaphysique et de morale, vol. 3:631-646.
} 
systems but does not account for under-actuation. It allows for the grasping of a ball, provided there is no walking. We recently lifted the restriction using a trick in modelling ${ }^{26}$ : the underactuated locomotory system is represented in the form of a virtual manipulator arm consisting of the imprints of steps which can fold like an accordion. We thereby artificially add redundancy to the system, and the general method can apply. An optimization algorithm is thus able to select a motion and coordinate the 30 motors of the HRP2 robot so that it can pick up a ball lying at its feet. In order to do so, the robot has to reverse. No specific locomotion program has specified this. The few backward steps that the robot takes to free the ball are an integral part of the data inputting task. Its entire body contributes to that.

I mentioned earlier that doing can provide instruments for understanding. Here is a fine example. On the basis of the principles that we have just seen and that he contributed to developing ${ }^{27}$, Yoshi Nakamura of Tokyo University recently developed a method enabling one to "see" the state of tension of all the muscles of a human being, based only on the observation of their movements. A set of cameras identify the position of the segments of the body in the surrounding space. They are coupled to a platform which constantly situates the pressure points of the subject on the ground. That is all. Could Etienne-Jules Marey, who invented chronophotography with the same aim of observing and understanding human motion, have conceived of that? Note that this is a technique which enables us to see the muscular system inside the body on the sole basis of the visual observation of its outside. There is no need for X-rays or scanners; the mathematical model is enough: simple, effective and cheap. The technique is based solely on the control of the function that links up the space of the task and the motor space. Henri Poincaré would have saluted the invention.

The principle of optimality underlying the study of relations between the motor space and the action space could not fail to resonate with the same principles studied in neurophysiology. If the brain - and the nervous system as a whole - has several hundred muscles to control the hand that is about to grasp an object, how does it go about dealing with this extraordinary complexity? The answer is "simple": evolution has established principles of muscular synergy, a form of automation that coordinates a set of muscles through a small number of parameters ${ }^{28}$. Even if in the end the motion takes place in very large spaces (motor space and

\footnotetext{
${ }^{26}$ Kanoun O, Laumond JP, Yoshida E (2011) Planning foot placements for a humanoid robot: a problem of inverse kinematics. The International Journal of Robotics Research, vol. 30, $\mathrm{n}^{\circ} 4: 476-485$, DOI: $10.1177 / 0278364910371238$.

${ }^{27}$ Nakamura Y (1991) Advanced Robotics: Redundancy and Optimization. Boston, Addison-Wesley Longman Publishing Co.

${ }^{28}$ Bernstein N (1967) The Coordination and Regulation of Movements. Oxford, Pergamon Press.
} 
configuration space), studies show that the choice ${ }^{29}$ is made in smaller sub-spaces which are consequences of coupling (when one walks, the right arm moves with the left leg) and principles of optimality. They reduce the dimension of the spaces to explore. The identification of this coupling and these principles is currently a key theme in computational neurosciences. A pioneer in the domain, Alain Berthoz, has found an apt name for the theory underpinning all this: "simplexity" ${ }^{30}$, a combination of these principles that life forms have invented to face world complexity. Together, and in collaboration with our colleague specialized in numerical optimization, Katja Mombaur, we have brought to light the principles that led up to the formation of locomotory trajectories. Take the following example: you enter a very big empty space (a shopping mall) that you have to cross through to get out (by a door). The space is vast. You are going to follow a trajectory and you think that it is yours. We have shown that everyone will actually follow very much the same trajectory. Our behaviour is stereotyped. It follows a principle that expresses a subtle combination between the comfort of movement, which leads one to anticipate the final goal to attain (being in front of the exit), and anchorage of the gaze on the door. The difficulty is to find this principle ${ }^{31}$, but once it has been found, it is very easy to implement it in a robot. That is how the humanoid robot HRP2 takes the same trajectories as those that we will use in its place.

The roboticist benefits from the principles governing the autonomy of life forms, while contributing to their study.

Was it necessary to do all that to get the HRP2 robot to work? The answer is no. Other robots use other approaches which are equally admissible from the point of view of the result.

But let us examine more closely the approach of today's humanoid robots. Most of them have flat feet and walk with bent legs ${ }^{32}$. This lack of suppleness is a consequence of the long process that led to their design. The main challenge of biped locomotion is balance. On a flat surface, flat feet form a support polygon. Provided that its centre of mass is above this polygon, the robot can remain perfectly immobile; it won't fall even if it is bumped slightly.

\footnotetext{
${ }^{29}$ Mechanics talk of "degrees of freedom", a fine expression in this context.

${ }^{30}$ Berthoz A (2012) Simplexity. Yale University Press.

${ }^{31}$ To that end we devised a resolution paradigm: the inverse optimum control. Usually, the engineer is faced with the following problem: given a system that has to be led to a desired state, and given a cost to optimize, what is the best strategy to apply? This is a problem of optimum control. In our case the problem is the opposite in so far as we observe a natural phenomenon and wonder which principle of optimality it obeys. The postulate of the existence of a principle of optimality may be questionable (it could be discussed in a future seminar), but at least it offers the roboticist an operational approach, and the neurophysiologist an angle of approach that establishes his/her own methods of validation. These studies resemble the methods of automatic identification and automatic learning in artificial intelligence.

${ }^{32}$ This is not the case of surprising biped machines (or even single-legged ones!) developed by Marc Raibert at MIT from the 1980s. His work produced the quadruped robots mentioned in the introduction. It was only very recently that he launched Petman, a new project for a humanoid robot.
} 
Designing a method of locomotion based on this principle ensures that at every moment the centre of mass is projected evenly on the polygon, the support of the two feet. Walking is then slow and laborious. It is necessary to do better. A clever model of stability was introduced in 2003 by Shuuji Kajita at the Japanese institute AIST $^{33}$, based on an idea introduced thirty years earlier by Miomir Vukobratović ${ }^{34}$ : all forces of reaction exerted by a flat floor on the surface of a body in contact with it can be reduced to the force exerted on a point called the centre of pressure. To ensure that the robot does not fall, it is enough for the point to remain above the support polygon. Force sensors to measure the effort placed under the robot's feet show the position of the centre of pressure at any point in time. Controlling the robot then consists in playing on the modification of the centre of mass, to ensure that the centre of pressure remains in the support polygon. The centre of mass no longer needs to verify the same constraint. The robot's walk is more fluid. Conceptually, the innovation is based on an approach to anthropomorphic walking that starts from the feet. It nevertheless requires the robot to have flat feet and to plan the position of its feet in advance.

Intuition suggests that we don't walk like that...

Neurophysiologists have a radically different approach: nature shows that bipeds walk with their head, not their feet! What does this provocative statement mean? In brief: the method of control referred to above is based on observation of the centre of pressure exerted by a person's feet on the ground (the information is given by sensors measuring effort, placed under the robot's feet). But neurophysiology teaches us that (living) bipeds stabilize their head in rotation in the sagittal plane ${ }^{35}$. The reference framework at the origin of the control of locomotion is in the head (the information is given by the vestibular system). Locomotion has to be envisaged as a process starting from the eyes and going towards the feet, and not the opposite. A robot will walk like a human only if it has an articulated head containing sensors capturing data on the position of its body (inertial units and other accelerometers). The design of the biped robot therefore has to integrate a complete body: it should not be designed step by step, first the legs, then the trunk, the arms and the head, as is often the case. The head is not only there to carry two cameras and to give a human appearance to the robot; it is an essential condition for the stabilization of the living biped's locomotion. It is a possible condition for the stabilization of the locomotion of humanoid robots.

\footnotetext{
${ }^{33}$ Kajita S et al (2003) Biped walking pattern generation by using preview control of zero-moment point. In: Proceedings of IEEE International Conference on Robotics and Automation, vol. 2:1620-1626, DOI: 10.1109/ROBOT.2003.1241826.

34 Vukobratović M, Stepanenko J (1972) On the stability of anthropomorphic systems. Mathematical Biosciences, vol. 15:1-37, DOI: 10.1016/0025-5564(72)90061-2.

${ }^{35}$ Berthoz A (1997) Le Sens du mouvement. Paris, Odile Jacob.
} 
The message is clear. The principle has been discovered; the roboticist just has to invent it. It is not enough to say; one also has to do. Moreover, the child him-/herself has to "invent" it over a long learning period. What are the mechanisms driving this learning? That is a question concerning neurophysiologists, psychophysicists and roboticists alike, and which fuels the fertile tension. Dialogue is possible: the probabilistic models, for example, are there to describe the processes. Markov chains and Bayesian inference enable us to structure and to explore very large databases in huge spaces. They also benefit from technological progress in computational power. The fact remains however that, even if the correlation between two variables enables roboticists to stabilize their robots, it says nothing about the causal relations. In any case, they pay little attention to that, condemned as they are to doing. And if they can invent a method that can do without this learning phase, so much the better ${ }^{36}$. I am deliberately over-stressing the point: we never protect ourselves enough from "dangerous analogies".

The past millennium ended with spectacular breakthroughs in information technology. The present one started with the robotics revolution. It is no longer simply a matter of manipulating data; now "things" are starting to move.

Manufacturing robotics discreetly imposed itself during the years of growth, without it really being held up as a factor of progress. Today, other adjectives qualify it, in a proliferation that I mentioned in the introduction: robotics is medical, personal, agrarian, sub-marine, aeronautic, spatial and military; it provides assistance and is used in exploration; it opens many routes for art development as evidenced in this book. Highly versatile, robotics is a flagship of technology today. We are expecting a great deal from it.

Since 2006 the Japanese Information and Robot Technology Programme has seen robotics as a means to address the question of the inversion of the age pyramid. Robot assistants are going to share our daily lives. They facilitate the mobility of elderly persons and provide the security for them to remain in their own home. Three years ago the US government launched the National Robotics Initiative, to which it allocated an annual grant of 70 million dollars. The aim is to develop robots capable of working in close collaboration with humans, in the manufacturing as well as medical, spatial and personal help fields. These programmes,

\footnotetext{
${ }^{36}$ We have seen that roboticists are capable of finding a method for driving a car. Whereas humans have to learn to drive, the models developed in robotics free the mobile robot of any learning phase. The equations of the motion of a car are known and mastered. Yet there is no point in humans knowing these equations; they still have to learn to drive.
} 
bringing together public authorities, industrial firms, universities and research institutes, mark a turning point and a new awareness that robots can leave the confines of their factories to work with humans and serve them. Humans thus become an integral part of the robot's environment.

As in surgical robotics, where models of deformation of the heart muscle are needed to automatically control the position of a clamp on a beating heart, reasoning in a world in which humans are stakeholders requires models of humans. The human-robot relationship is now a central theme in robotics research. Alone it justifies - as if it were necessary - the multidisciplinary researches mentioned above.

These researches are indispensable, but insufficient. Questions of security in robots' physical interaction with humans are crucial. They transcend issues of security and reliability of algorithms and programmes as they are usually addressed in computing. They concern the design of new, more compliant motors, new, more flexible materials, and new, smaller and more precise sensors. The spectrum is wide: from micro- (even nano-) technologies to questions on the computational foundations of anthropomorphic action. The ambition is huge. The world is surprised that no robot effectively intervened in the Fukushima nuclear plant. Actually, the intervention robots that make the headlines of our newspapers are still far from being operational. In response to a message of solidarity that I had sent him, Yoshi Nakamura wrote to me on 20 March 2011, saying: "Many robotics researchers including me were shocked by the fact that we have no weapon against the difficulty. Even engineering may have shown its immaturity." (sic). This statement is dreadful, coming from one of the world's leading roboticists.

We need to be wary of hype. Research needs time. Innovation must of course be stimulated (that is the role of large programmes) but it is difficult to control. It often appears where it is least expected; we have seen many examples of this, especially in information technology. What can be said about Nao, the small robots that educational teams use today to help autistic children? No "order" was put through, yet what a fine bit of innovation if a little machine communicating by voice and movement can help these children out of their isolation, at least partially. Recent years have shown that it is difficult to predict the impact of technological progress. Steve Jobs did not meet needs; he created needs that have become essential today, yet which we did without yesterday. That is where his genius lies.

As regards robotics, its impact is going to affect many sectors; we have listed the most probable. How are we going to adapt? Easily. Humans are highly adaptable to new technologies. The wheel led us to tar our landscapes and we find it difficult to switch off our 
mobile phones. Technological innovation is always a death sentence for a certain know-how (savoir faire) and for certain social conventions (savoir vivre). In this sense, robotics should also prompt us to ask ourselves certain questions. The roboticist can tell us what it is about and that is what I have endeavoured to do - but unfortunately nothing more. Faced with Athena, he is the eternal one who limps. He has nothing to say on what he knows about civilization; he only knows how to $d o^{37}$ !

Let us conclude Apollodorus' text. The episode ends as follows:

As [Athena] was fleeing, Erichtonius came to birth from the seed that had fallen on the earth. ${ }^{38}$

Erichthonius was one of the first kings of Athens. That is no minor detail. So, the attempt to possess was not sterile! That is clearly what we have seen: it is already transforming our lifestyles.

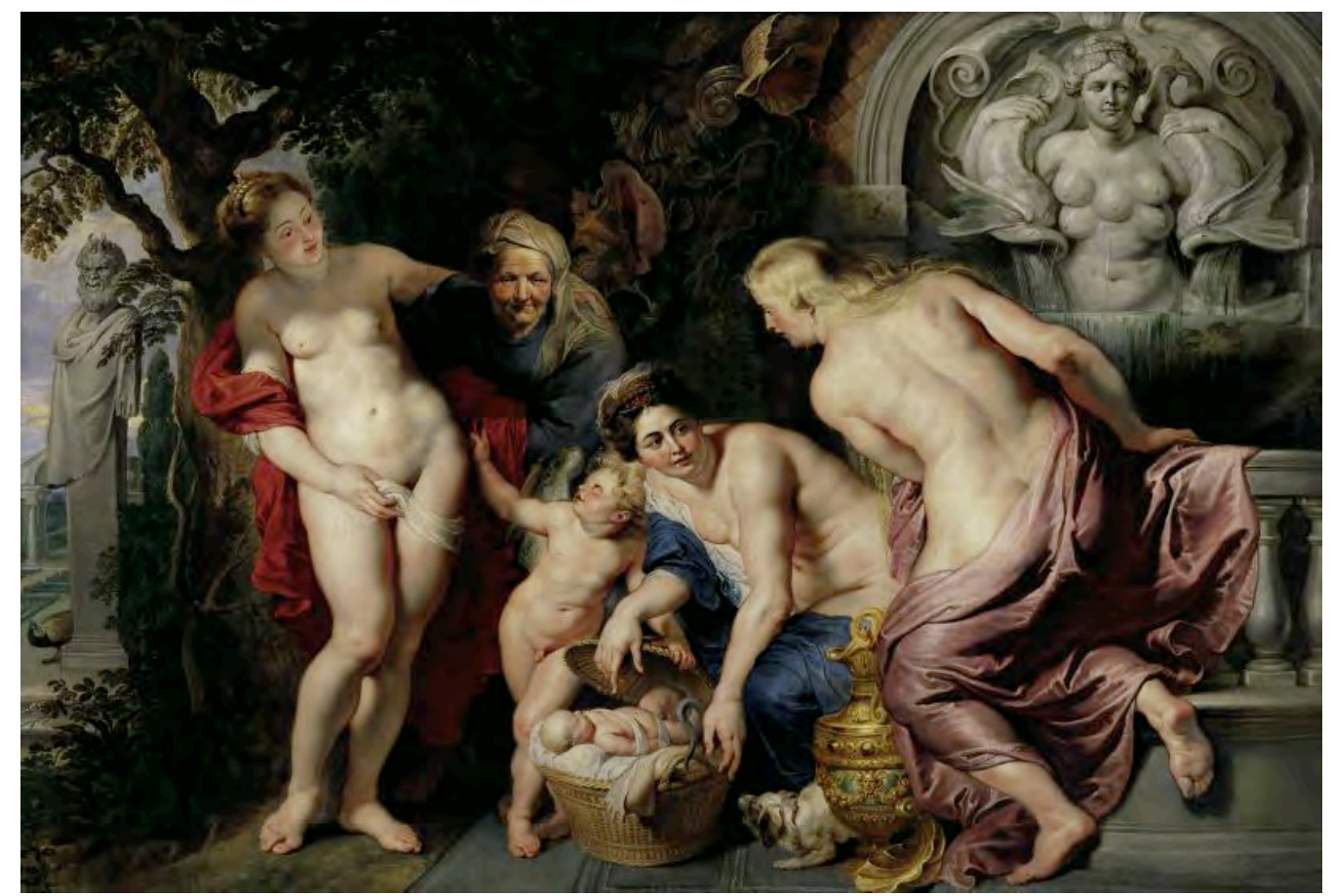

The finding of Erichthonius, Pierre Paul Rubens (circa 1616)

(C) LIECHTENSTEIN. The Princely Collections, Vaduz-Vienna

\footnotetext{
${ }^{37}$ Does what applies to the roboticist also apply to the citizen robotics researcher? I think it does, but I must admit that this is where I reach uncertain shores of my reference to mythology.

${ }^{38}$ Hard, op. cit.
} 